(C) Коллектив авторов., 2009

УДК 616.89+616.89-008.441.13

КРАТКИЙ ОБЗОР ПРОБЛЕМЫ «ДВОЙНОГО ДИАГНОЗА» (СОЧЕТАНИЕ ПСИХИЧЕСКИХ РАССТРОЙСТВ И РАССТРОЙСТВ ЗАВИСИМОСТИ ОТ ПСИХОАКТИВНЫХ ВЕЩЕСТВ)

\author{
Е.А.Шитов, Д.Н.Киселев, Д.И.Шустов
}

Рязанский государственный медицинский университет имени академика И.П.Павлова

\begin{abstract}
Проблема коморбидности психических заболеваний и зависимости от алкоголя, наркотиков и других психоактивных веществ приобретает в настоящее время особую актуальность в связи с масштабами этой сочетанной патологии. Среди больных алкоголизмом, наркоманиями и токсикоманиями почти пятая часть обнаруживает процессуальные эндогенные психические заболевания. По тем же данным среди больных шизофрений и маниакально-депрессивным психозом не менее одной трети злоупотребляют различными психоактивными веществами. Авторы провели широкий обзор данных литературы (и, прежде всего, зарубежных источников) об актуальности проблемы коморбидных расстройств, их распространенности в различных странах, рассмотрели современные взгляды на патогенез таких состояний, а также социальные и клинические проблемы «двойного диагноза».

Ключевые слова: качество жизни, тревога, депрессия, психоактивные
\end{abstract} вещества

Проблема коморбидности психических заболеваний и зависимости от алкоголя, наркотиков и других психоактивных веществ (ПАВ) приобретает в настоящее время особую актуальность в связи с масштабами этой сочетанной патологии.

По данным ННЦ наркологии исследования последних двух десятилетий показывают, что среди больных алкоголизмом, наркоманиями и токсикоманиями почти пятая часть (20\%) обнаруживает процессуальные эндогенные психические заболевания. По их же данным среди больных шизофрений и маниакальнодепрессивным психозом не менее одной трети (30\%) злоупотребляют различными ПАВ [2]. Исследование, проведенное Московским НИИ психиатрии при изучении контингента больных шизофренией, зарегистрированных в психоневрологических диспансерах г. Москвы, показало, что в 12,2\% всех случаев шизофрении отмечается ее сочетание с алкоголизмом [1]. Причем 50\% случаев такого сочетания составляют случаи сформированного алкоголизма (сформированы патологическое влечение к алкоголю, запойное пьянство, абстинентный синдром), а в $50 \%$ случаев диагностирован только симптоматический алкоголизм или хроническая алкогольная интоксикация (многодневное пьянство, повышенная толерантность к алкоголю, без признаков абстиненции и возможностью эпизодического 
употребления спиртного без утраты количественного контроля). Таким образом, делают вывод исследователи, распространенность алкоголизма среди больных шизофренией соответствует таковой среди населения в целом - около $6 \%$ [1].

В тоже время, данные зарубежной литературы предполагают, что почти 50\% пациентов с шизофренией имеют сопутствующее расстройство, вызванное употреблением психоактивных веществ - Substance use disorder (SUD). Наиболее часто встречается сочетание шизофрении и алкогольной и/или каннабиноидной зависимости (приблизительно в три раза чаще, чем в общей популяции) [12]. Что же касается в целом сочетания тяжелых психических расстройств и болезней зависимости, то зарубежные исследования показывают следующие данные. 20 $60 \%$ больных страдающих тяжелыми психическими расстройствами имеют сопутствующее расстройство, вызванное употреблением ПАВ [7].

Влияние зависимости от психоактивных веществ на течение шизофрении.

Со времени описания Гретером в 1909 году шизофрении, сочетающейся с алкоголизмом, сформировались три основные точки зрения относительно влияния алкогольной зависимости и злоупотребления алкоголем на течение шизофрении. 1) Алкоголизм смягчает течение шизофрении, так как многие пьющие больные шизофренией более сохранны в отличие от непьющих. 2) Алкоголизм утяжеляет течение шизофрении, так как после запоев возникают психозы и обостряется течение эндогенного заболевания. 3) Алкоголизм не смягчает течение шизофрении, так как он присоединяется к наиболее благоприятно текущему эндогенному заболеванию и редуцируется по мере нарастания дефекта.

Ответ на данный вопрос получен в исследовании НИИ психиатрии при сопоставлении различий у больных шизофренией и шизофренией в сочетании с алкоголизмом с учетом встречаемости разных форм шизофренического процесса. При сочетании двух заболеваний не встречается злокачественная шизофрения, начинающаяся в молодом возрасте, очень редко встречается рекуррентная шизофрения (шизоаффективный психоз), почти в 2 раза чаще встречается благоприятно протекающая шубообразная шизофрения. Эти данные, учитывая тенденцию к прекращению пьянства при нарастании дефекта, говорят о следующем: алкоголизм сочетается преимущественно с наиболее благоприятно протекающей шизофренией. Исключение составляет только рекурентная шизофрения, при которой алкоголизм не формируется или же формируется весьма редко и не влияет на структуру психотических состояний [1].

Сочетание алкоголизма и шизофрении ухудшает социальное положение больных. При сочетании алкоголизма с шизофрений чаще наблюдаются разводы, значительно реже больные получают высшее или среднее образование. При сочетании двух заболеваний увеличивается число инвалидов II группы. О более выраженной социальной декомпенсации больных с сочетанной патологией свидетельствует более частое совершение больными с «двойным диагнозом» общественно опасных действий [1].

Зарубежные исследователи проблемы отмечают, что пациенты с «двойным диагнозом» склонны к неблагоприятным исходам по сравнению с пациентами больными только шизофренией по следующим позициям. Увеличение тяжести симптомов, увеличение частоты госпитализации, сопутствующих инфекционных заболеваний (в том числе ВИЧ инфекция), случаев насилия, виктимизации, жилищной неустроенности, увеличение случаев отказа от приема лекарств и, в целом, большей резистентности к психофармакотерапии и низкой вовлеченности в 
лечебный процесс (нонкомплаенс). «Двойной диагноз» увеличивает финансовые затраты на таких пациентов и способствует развитию эмоциональных трудностей при контакте - для пациентов, членов из семей и системы психического здоровья $[7,12,26]$.

«Двойной диагноз» шизофрении и SUD отмечен не только у пациентов с хроническим течением заболевания. Уровень расстройств, вызванных употреблением (РВУ) каннабиноидов составляет 53 \% пациентов с первым эпизодом шизофренического психоза [14]. Употребление гашиша связано с более ранним возрастом начала шизофрении [14], увеличенным риском развития психоза [18], более высоким уровнем рецидивов после ремиссии первого эпизода острого психотического состояния [23]. Стратегии помощи пациентам, призванные уменьшить употребление ПАВ, как во время первого эпизода, так и в течение всего курса болезни, необходимы для достижения оптимального исхода для пациентов с шизофренией.

Исследование [12] не выявило связи между отдельными специфическими симптомами шизофрении и выбором определенного психоактивного вещества для злоупотребления. Скорее выбор наркотика пациентом с шизофренией происходит в соответствии с наиболее распространенными в данной популяции наркотическими веществами.

\section{Теории возникновения «двойного диагноза» шизофрении и SUD.}

Многие теории были призваны объяснить высокую распространенность SUD у пациентов с шизофренией $[25,29]$.

Во-первых, некоторые авторы предложили нервные модели дистресс-диатеза, которые предполагают, что нейробиологическая уязвимость взаимодействует со стрессами в окружении (такие стрессы, как употребление ПАВ), что способно у лиц с повышенной уязвимостью ускорить начало шизофрении или рецедива психоза [15]. Поддержка этой модели была найдена в исследованиях отмечающих, что употребление ПАВ связано с более ранним возрастом начала шизофрении $[14,18]$. Недавние исследования обнаружили, что употребление гашиша подростками, которые имеют «высокую продукцию» catechol $O$-methyltransferase (Val/Val) связано с более высоким риском развития психоза в юности [24]. и, очевидно, что у пациентов с шизофренией весьма вероятен рецедив психоза после употребление даже небольшого количества психоактивного вещества [10]. Пациенты с шизофренией, таким образом, выглядят более уязвимыми к эффектам психоактивных веществ, когда небольшой уровень злоупотребление алкоголя и наркотиков способен привести к неблагоприятным последствиям.

Во-вторых, гипотеза накопления факторов риска [25] предлагает, что у больных шизофренией больше риск развития злоупотребления ПАВ в виду совокупности факторов: плохое когнитивное, социальное, образовательное, профессиональное функционирование вместе с бедностью, виктимизацией и подверженностью к девиантному и/или зависимому от ПАВ поведению в семье и ближайшем социальном окружении. Все это известно как факторы риска развития злоупотребления ПАВ и зависимости от ПАВ. В тоже время, несмотря на то, что у этой модели есть сильные доводы за, ни одно исследование еще не проверило тот факт, что накопление факторов риска лежит в основе более высокого уровня развития зависимости от ПАВ у пациентах с шизофренией.

В-третьих, гипотеза самолечения [20], предлагает это пациенты с шизофренией используют психоактивные вещества, чтобы уменьшить симптомы психического 
расстройства или уменьшить побочные эффекты антипсихотических лекарств. Несмотря на то, что данная теория не лишена здравого смысла, большинство исследований не отмечают наличие связей между злоупотреблением ПАВ и уменьшением выраженности продуктивных или дефицитарных симптомов заболевания, или вызванных лечением экстрапирамидных побочных эффектов [28]. A исследования, которые демонстрируют повышенный уровень SUD у лиц с первым эпизодом психоза, которые начали употребление ПАВ задолго до начала антипсихотического лечения это дополнительный аргумент против этой теории [14].

Две группы исследователей, Green et al [14] и Chambers et al. [6], предложили альтернативную модель, которая названа дисфункция схемы вознаграждения (reward circuitry). Исследования на животных и человеческие исследования указывают то, что при шизофрении дисфункциональны допаминовые системы вознаграждения. У пациентов с шизофренией злоупотребление ПАВ может модулировать эту нарушенную систему вознаграждения мозга через нейрональное увеличение обнаружения сигналов этой допаминовой системой [27]. Таким образом, основание для злоупотребления ПАВ может быть связано с трудностями этих пациент в переживании "нормального " уровня вознаграждения от окружения и способности ПАВ увеличить и компенсировать дефицит системы вознаграждения $[6,29]$.

\section{Сочетание аффективных расстройств и расстройств зависимости от психоактивных веществ.}

Аффективные расстройства - другая группа расстройств, часто сочетающаяся с зависимостью от ПАВ $[9,22]$. Причем, также как и в случае шизофрении, это сочетание ведет к ухудшению исхода заболевания [19], включая увеличенный риск суицида $[21,30]$.

Исследование, проведенное в США среди американских граждан в возрасте от 15 до 54 лет (величина выборки 8098 человек), выявило, что у $6.5 \%$ больных алкоголизмом мужчин и $10.6 \%$ больных алкоголизмом женщин были в анамнезе маниакальные эпизоды [3].

Исследования, проводимые среди больных биполярным расстройством, оценивают уровень сопутствующего расстройства зависимости от алкоголя колеблющимся от 6 до 60\% (в большинстве исследований - 30\%), а уровень сопутствующего расстройства зависимости от наркотиков от 14 до 60\% [5]. Так среди 392 пациентов, госпитализированных по поводу маниакального или смешанного эпизода, уровень злоупотребления алкоголем составил 48,5 \%, других наркотиков $43,9 \%$, и любых ПАВ почти $60 \%$ [5].

У мужчин с биполярным расстройством уровень злоупотребления ПАВ выше, чем у женщин (59,7 \% против 37,8 \% для алкоголя; 54,5\% против 33,8 \% для других наркотиков) [5]. Уровень злоупотребления марихуаной был выше мужчин, чем у женщин, уровни злоупотребления кокаином и опиатами равны [5].

Другое исследование подтвердило эти данные. Обзор 131 истории болезни пациентов с биполярным расстройством, показал, что биполярные мужчины в два раза чаще имели коморбидное расстройство зависимости от ПАВ, чем женщины. Женщины с биполярным расстройством в четыре раза чаще употребляли алкоголь и в семь раз чаще злоупотребляли наркотиками, чем женщины в общей популяции $[16]$. 
Среди биполярных пациентов, совершивших суицид, у 10 из 18 жертв суицида мужского пола были больны еще и алкоголизмом, но ни у одной из 13 совершивших суицид женщин алкоголизм не был выявлен [17]. У пожилых пациентов были более низкие нормы активного злоупотребления ПАВ.

Описаны следующие осложнения после злоупотребления ПАВ у биполярных пациентов. Чаще втречаются смешанные маниакальные эпизоды и быстрая смена фаз [11], более длительное время восстановления [11], более высокая распространенность соматических расстройств, включая болезни печени [3], большее число попыток самоубийства [13], и завершенных случаев самоубийства $[3,4]$. Так, например, при исследовании 337 пациентов с эпизодом большого аффективного расстройства, уровень попыток суицида был $38,4 \%$ в группе со смешенным аффективным расстройством и алкоголизмом против $21.7 \%$ в группе без алкогольной зависимости $(p<0,005)$ [4].

Недостаток родительского внимания в детстве может быть предрасположением к развитию у биполярных пациентов злоупотребления ПАВ, и увеличенного риска для быстрой смены фаз и суицидальных попыток [17].

Злоупотребление наркотиками может приводить к ошибочной диагностики биполярного расстройства в связи со схожей с маниакальным эпизодом картиной интоксикации психстимуляторами (кокаин, метамфетамин).

\section{Выводы}

Таким образом, актуальность проблемы «двойного диагноза» - сочетания тяжелых психических расстройств (депрессивное расстройство и шизофрения) и зависимости от психоактивных веществ - достаточно высока. Это связано с довольно широкой распространенностью такого коморбидного состояния и их взаимоотягощающим влиянием. Мы провели обзор наиболее современных исследований проблемы «двойного диагноза», оценили уровень распространенности коморбидных расстройств в России и зарубежом, рассмотрели современные взгляды на патогенез развития коморбидных расстройств.

\section{ЛИТЕРАТУРА}

1. Гофман А.Г. Шизофрения, сочетающаяся с алкоголизмом (клиническая картина и лечение) / А.Г.Гофман, К.Д.Малков, И.В.Шлемина // Психиатрия и психофармакотерапия. - 2008 - Т.10, № 3. - С. 23-27.

2. Чирко В.В. Эндогенные психозы и зависимость от психоактивных веществ / В.В. Чирко, Э.С.Дроздов // Руководство по наркологии: в 2 т. / под ред. Н.Н. Иванца. - М.: Медпрактика, 2002. - Т.1. - С 385-407.

3. Albanese M.J. Divalproex sodium in substance abusers with mood disorder / M.J. Albanese, R.C. Clodfelter Jr., E.J. Khantzian // J. Clin. Psychiatry - 2000 - № 61 - P. $916-21$

4. Attempted suicide and alcoholism in bipolar disorder: clinical and familial relationships / J.B. Potash [et al.] // Am J Psychiatry. - 2000. - № 157. - P.2048-2050.

5. Cassidy F. Substance abuse in bipolar disorder / F.Cassidy, E.P.Ahearn, B.J. Carroll // Bipolar Disord. - 2001. - № 3. - P.181-188.

6. Chambers A.R. A neurobiological basis for substance abuse comorbidity in schizophrenia / A.R. Chambers, J.H. Krystal, D.W. Self // Biol. Psychiatry. - 2001. - № 50. - P. 71-83. 
7. Characteristics of Subgroups of Indiviuals With Psychotic Illness and a Comorbid Substance Use Disorder / H. Miles [et al.] // Psychiatric Services. - 2003. Vol. 54, № 4. - P. 554-561.

8. Clozapine for comorbid substance use disorder and schizophrenia: do patients with schizophrenia have a reward-deficiency syndrome that can be ameliorated by clozapine? / A.I. Green [et al.] // Harv. Rev. Psychiatry. - 1999. - № 6. - P.287-296.

9. Comorbidity of mental disorders with alcohol and other drug abuse / D.A. Regier [et al.] // JAMA. - 1990.- № 264. - P.2511-2518.

10. Delta-9-tetrahydrocannabinol effects in schizophrenia: implications for cognition, psychosis, and addiction / D.C. D’Souza [et al.] // Biol. Psychiatry. - 2005. № 57. - P.594-608.

11. Differential outcome of pure manic, mixed/cycling, and pure depressive episodes in patients with bipolar illness / M.B. Keller S // JAMA. - 1986. - № 255. - P.31383142 .

12. Dixon L. Dual diagnosis of substance abuse in schizophrenia: prevalence and impact on outcomes / L.Dixon // Schizophr. Res. - 1999. - № 35(Suppl). - P. S93-S100.

13. Fawcett J. Predictors of early suicide: identification and appropriate intervention / J. Fawcett // J. Clin. Psychiatry. - 1988. - № 49(Suppl). - P. 7-8.

14. First-episode schizophrenia-related psychosis and substance use disorders: acute response to olanzapine and haloperidol / A.I. Green [et al.] // Schizophr. Res. - 2004 Vol.66,№2-3. - P.125-135.

15. Fowles D.C. Schizophrenia: diathesis-stress revisited. / D.C.Fowles // Annu. Rev. Psychol. - 1992. - № 43. - P.303-336,

16. Gender and bipolar illness / V. Hendrick [et al.] // J. Clin. Psychiatry. - 2000. -№ 61. - P. 393-396.

17. Goldberg J.F. Clinical correlates of childhood and adolescent adjustment in adult patients with bipolar disorder. / J.F.Goldberg, C.L.Ernst // J. Nerv. Ment. Dis. - 2004. № 192. - P.187-192.

18. Hambrecht M. Substance abuse and the onset of schizophrenia. / M. Hambrecht, H. Häfner // Biol Psychiatry. - 1996 - № 40. - P.1155-1163.

19. Hasin D.S. Comorbidity of alcohol, drug, and psychiatric disorders: epidemiology / D.S. Hasin, E.V. Nunes // Dual Diagnosis and Treatment: Substance Abuse and Psychiatric Disorders / eds.: H. Kranzler, B.J. Rounsaville. - New York: NY: Marcel Decker Inc,1988.

20. Khantzian E.J. The self-medication hypothesis of substance use disorders: a reconsideration and recent applications / E.J. Khantzian // Harv Rev Psychiatry. - 1997. № 4. - P.231-244.

21. Levy J.C. Suicidality, depression, and substance abuse in adolescence / J.C. Levy, E.Y. Deykin // Am J Psychiatry. - 1989. - № 146. - P.1462-1467.

22. Lifetime co-occurrence of DSM-III-R alcohol abuse and dependence with other psychiatric disorders in the National Comorbidity Survey / R.C. Kessler [et al.] // Arch Gen Psychiatry. - 1997. - № 54. - P.313-321.

23. Linszen D Cannabis abuse and the course of recent-onset schizophrenic disorders / D. Linszen, P. Dingemans, M. Lenior // Arch Gen Psychiatry. - 1994. - № 51. - P.273279.

24. Moderation of the effect of adolescent-onset cannabis use on adult psychosis by a functional polymorphism in the catechol-O-methyltransferase gene: longitudinal evidence 
of a gene environment interaction / A. Caspi [et al.] // Biol. Psychiatry. - 2005. - № 57. P. 1117-1127.

25. Mueser K. Dual diagnosis: a review of etiological theories / K. Mueser, R. Drake, M. Wallach // Addict Behav. - 1998. - № 23. - P.717-734.

26. Naltrexone Study Collaboration Group: Naltrexone augmentation of neuroleptic treatment in alcohol abusing patients with schizophrenia / I.L. Petrakis [et al.] // Psychopharmacology. - 2004. - № 172. - P.291-297.

27. Nissel M. Nicotine dependence, midbrain dopamine systems, and psychiatric disorders / M. Nissel, G.G. Nomikos, T.H. Svensson // Pharmacol Toxicol. - 1995. - № 76. - P.157-162.

28. Relationships between symptoms of schizophrenia and substance abuse / M. Brunette [et al.] // J. Nerv. Ment. Dis. - 1997. - № 185. - P.13-20.

29. Roth R.M.. Treatment of substance use disorders in schizophrenia: a unifying neurobiological mechanism? / R.M. Roth, M.F. Brunette, A.I. Green // Curr Psychiatry Rep. - 2005. - № 7. - P.283-291.

30. Suicide attempts in major affective disorder patients with comorbid substance use disorders / L. Tondo [et al.] // J Clin Psychiatry. - 1999. - № 60(Suppl. 2). - P.63-69.

\title{
COMORBIDITY OF MENTAL DISORDERS WITH ALCOHOL AND DRUG ABUSE (REVUE OF THE PROBLEM DUAL DIAGNOSE)
}

\author{
E.A. Shytov, D.N.Kiselev, D.I.Shustov
}

The rate of substance-use disorders in patients with severe mental illnesses, such as schizophrenia and bipolar disorder, is higher than the rate observed in the general population and is associated with significant morbidity and mortality. The co-occurrence of severe mental illness and substance use disorder, or dual diagnosis, is prevalent and is associated with significant clinical and social problems. There are revue of the current researches the problem of dual diagnosis. We discuss the rate of substance-use disorders in patients with schizophrenia and bipolar disorder, most clinical and social problems of these patients, and theories have been advanced to explain the elevated prevalence of substance use disorder in people with psychic disorders. 